\title{
A carbonate controlled-addition method for size-controlled calcium carbonate spheres by carboxylic acid-terminated poly(amidoamine) dendrimers
}

\author{
Yuka Tanaka and Kensuke Naka
}

Size-controlled calcium carbonate particles were obtained using a 'carbonate controlled-addition method' with G0.5 poly(amidoamine) (PAMAM) dendrimer with carboxylate groups at the external surface. An aqueous ammonium carbonate solution was added to an aqueous solution of the dendrimer and $\mathrm{CaCl}_{2}$ at different time periods $(3 \mathrm{~min}, 1 \mathrm{~h}$ or $24 \mathrm{~h}$ ) and was stirred for 1 day. Both crystal phases obtained at incubation times of 1 and $24 \mathrm{~h}$ were vaterite. The dendrimer-CaCl${ }_{2}$ solution incubated for $3 \mathrm{~min}$ produced vaterite particles that coexisted with calcite. The average particle size of the spheres decreased from $2.2 \pm 0.2$ to $0.61 \pm 0.24 \mu \mathrm{m}$ with an increase in the incubation time of the dendrimer- $\mathrm{CaCl}_{2}$ solution. When the products were kept in the reaction mixtures for 3 days, the $\mathrm{CaCO}_{3}$ phase of the precipitates obtained after incubating the dendrimer$\mathrm{CaCl}_{2}$ solution for $3 \mathrm{~min}$ and $1 \mathrm{~h}$ was calcite. However, the product obtained after incubating for $24 \mathrm{~h}$ was vaterite. The present results demonstrate that the interaction and the reaction kinetics of the dendrimer- $\mathrm{Ca}^{2+}$ complex have an important role in the mineralization and stabilization of $\mathrm{CaCO}_{3}$ particles.

Polymer Journal (2010) 42, 676-683; doi:10.1038/pj.2010.50; published online 16 June 2010

Keywords: calcite; calcium carbonate; carbonate controlled-addition method; dendrimer; mineralization; vaterite

\section{INTRODUCTION}

Biomimetic synthesis of $\mathrm{CaCO}_{3}$ crystals in the presence of organic templates has been intensively studied. ${ }^{1,2}$ Most researchers' interests lie in understanding how organized inorganic materials with complex morphological forms can be produced through a biomineralization process and how such complexity can be reproducibly synthesized in biomimetic systems. ${ }^{2}$ Construction of organic-inorganic hybrid materials with controlled mineralization is interesting for both organic and inorganic chemists because they want to understand the mechanism behind the natural biomineralization process, as well as seek industrial and technological applications. ${ }^{3-6}$ The major inorganic material produced in natural organisms is calcium carbonate. Calcium carbonate is an attractive model mineral for studies in the laboratory because its crystals are easily characterized and the morphology of $\mathrm{CaCO}_{3}$ has been the subject to be controlled in biomineralization processes. $^{7,8}$

Most efforts toward $\mathrm{CaCO}_{3}$ mineralization have focused on the influence of specific additives and/or templates on the formation of $\mathrm{CaCO}_{3}$, as well as the kinetics and mechanisms of the subsequent phase transformation and morphology control. However, few studies have been applied specifically to binding kinetics and the mechanisms of polyelectrolyte- $\mathrm{Ca}^{2+}$ complexes as they have been to the mineralization process of $\mathrm{CaCO}_{3}$. Therefore, studying the effects of the kinetics and mechanisms of the interaction between a polymer and $\mathrm{Ca}^{2+}$ on the crystallization process of $\mathrm{CaCO}_{3}$ would provide an opportunity to gain a fundamental understanding of the biomineralization process. Recently, we introduced a new, simple method called a 'carbonate controlled-addition method' that uses poly(acrylic acid) (PAA). In this method, carbonate ions were added to a PAA- $\mathrm{CaCl}_{2}$ aqueous solution at different time periods. ${ }^{9,10}$ The nucleation and mineralization of $\mathrm{CaCO}_{3}$ were mediated by the coordination structures of PAA and $\mathrm{Ca}^{2+}$ complexes. Stable amorphous calcium carbonate (ACC) composite particles with size-controlled monodispersed spheres were obtained by this simple method. The average particle size of the ACC spheres increased from $(1.8 \pm 0.4) \times 10^{2}$ to $(5.5 \pm 1.2) \times 10^{2} \mathrm{~nm}$ with an increase in the incubation time of the $\mathrm{PAA}-\mathrm{CaCl}_{2}$ solution from $3 \mathrm{~min}$ to $24 \mathrm{~h}$, respectively. We demonstrated that the interaction and reaction kinetics of PAA- $\mathrm{Ca}^{2+}$ complexes have an important role in particle size and in the stability of ACC products.

Crystallization of $\mathrm{CaCO}_{3}$ in the presence of various synthetic nonpeptide polymers has been investigated as a model of biomineralization. ${ }^{3-6}$ 
For such synthetic linear polymers, it has been difficult to unambiguously assign a structure-function relationship in the context of their activity in crystallization assays because they mostly occur in a random-coil conformation. Dendrimers are monodispersed macromolecules with a regular and highly branched three-dimensional architecture. ${ }^{11}$ Because of unique and well-defined secondary structures of dendrimers, the starburst dendrimer should be a good candidate for studying inorganic crystallization. We previously showed that crystallization of $\mathrm{CaCO}_{3}$ in the presence of poly(amidoamine) (PAMAM) dendrimers with carboxylate groups at the external surfaces resulted in the formation of stable spherical vaterite crystals. ${ }^{12,13}$ The vaterite surfaces were stabilized by carboxylate-terminated dendrimers in an aqueous solution to prevent phase transformation. Furthermore, as the generation number of PAMAM dendrimers increased from G1.5 to G3.5, the sizes of spherical vaterite particles decreased from $5.5 \pm 1.1$ to $2.3 \pm 0.7 \mu \mathrm{m}$, which may be due to differences in the coordination ability of PAMAM dendrimers. These results suggest that anionic PAMAM dendrimers function as effective protective agents for the most unstable vaterite crystal in an aqueous solution.

In this study, we applied the 'carbonate controlled-addition method' with PAMAM dendrimers with carboxylate groups at the external surface (Scheme 1). We found that the particle sizes of the as-synthesized vaterite spheres can be controlled by changing the incubation time of the G0.5 PAMAM dendrimer ( $\mathrm{G} 0.5)-\mathrm{CaCl}_{2}$ solution before the addition of carbonate ions. The minimum average particle size of the spheres, at $0.69 \pm 0.07 \mu \mathrm{m}$, significantly decreased with respect to our previous reports. ${ }^{12,13}$ We also found that the stability of vaterite spheres increased with an increase in the incubation time of the $\mathrm{G} 0.5-\mathrm{CaCl}_{2}$ solution, even though the contents of the organic parts in the three products were almost the same. We studied the effects of the interaction and the reaction kinetics of the dendrimer with $\mathrm{Ca}^{2+}$ and $\mathrm{H}_{2} \mathrm{O}$ on the mineralization of $\mathrm{CaCO}_{3}$. This is a simple way to control the mineralization of $\mathrm{CaCO}_{3}$ by changing the incubation time of the dendrimer- $\mathrm{CaCl}_{2}$ complexation process (Figure 1).

\section{EXPERIMENTAL PROCEDURE}

\section{Materials}

Carboxylic acid-terminated half-generation PAMAM (G0.5 and G1.5 PAMAM) dendrimers were prepared by hydrolysis of corresponding methyl ester-terminated PAMAM dendrimers, which were prepared according to the reported procedure. ${ }^{14,15}$ Each half-generation dendrimer was purified by size-exclusion chromatography (LH-20) using a methanol eluent. The ${ }^{1} \mathrm{H}$ nuclear magnetic resonance analyses of the G0.5 and G1.5 PAMAM dendrimers were identical to those obtained from Aldrich. Calcium chloride and ammonium carbonate were purchased from WAKO Pure Chemical Industries, Ltd (Osaka, Japan).

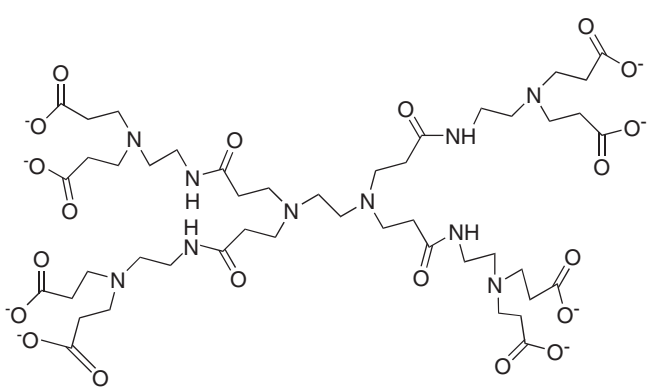

G0.5

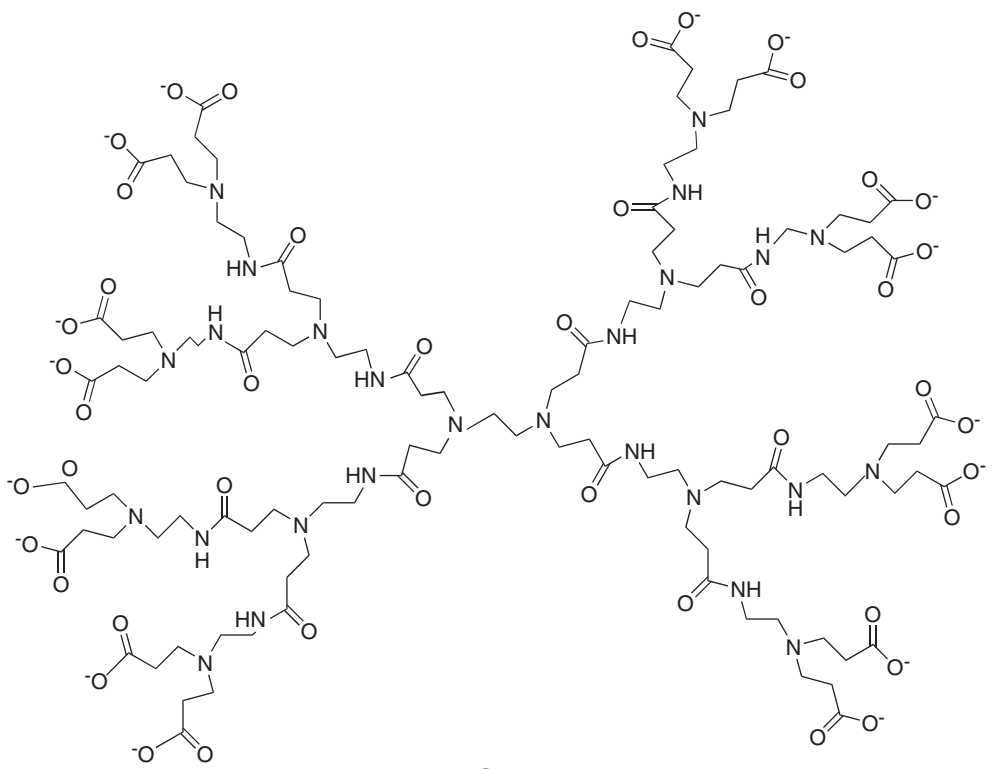

G1.5

Scheme 1 Half-generation poly(amidoamine) (G0.5 and G1.5 PAMAM) dendrimers.

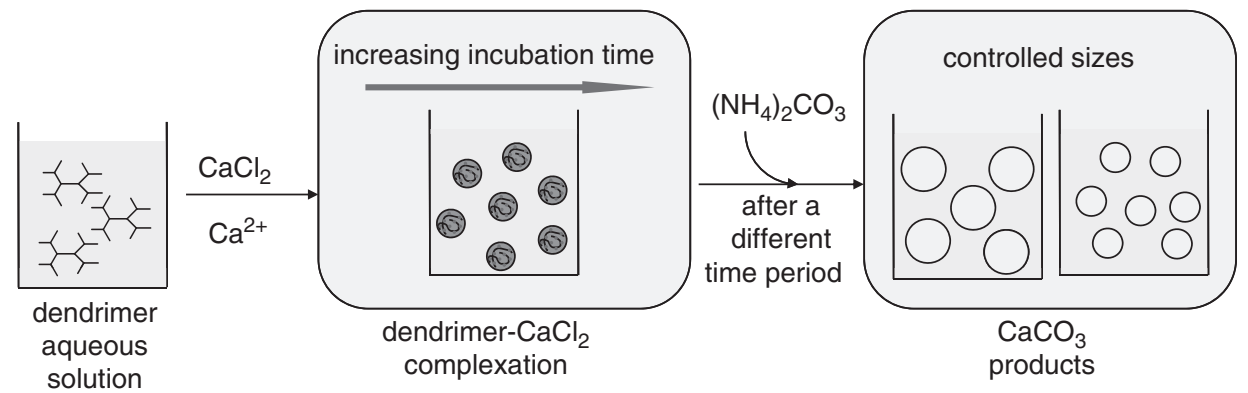

Figure 1 Schematic illustration of the carbonate controlled-addition method. 


\section{Measurements}

X-ray diffraction patterns were recorded on a Rigaku Mini Flex/AW (Rigaku, Akishima, Japan) with $\mathrm{CuK} \alpha$ radiation $(\lambda=1.5406 \AA)$ in $\theta / 2 \theta$ mode at room temperature. The $2 \theta$ scan data were collected with a $0.01^{\circ}$ interval and a scan speed of $1^{\circ}(2 \theta) \mathrm{min}^{-1}$. Fourier transform infrared (FT-IR) spectra were recorded with a JASCO FT/IR-4100 spectrometer (JASCO, Tokyo, Japan) with a $\mathrm{KBr}$ pellet. Morphologies of the $\mathrm{CaCO}_{3}$ particles were observed using scanning electron microscopy (SEM) of KEYENCE EV-800 (KEYENCE, Osaka, Japan) at $10 \mathrm{kV}$. Thermogravimetric analysis (TGA) was measured on a TG/DTA 6200 (SEIKO Instruments, Inc., Chiba, Japan) to a temperature of $900^{\circ} \mathrm{C}$ at a heating rate of $10^{\circ} \mathrm{C} / \mathrm{min}$ in air.

\section{Precipitation of $\mathrm{CaCO}_{3}$}

Standard preparation of the precipitation of $\mathrm{CaCO}_{3}$ was carried out as follows. First, a stock aqueous solution of the G0.5 PAMAM dendrimer ( $1 \mathrm{mM})$ was prepared in distilled water, and the $\mathrm{pH}$ value was adjusted to 11 using a dilute aqueous solution of $\mathrm{NaOH}$. Then, $2.5 \mathrm{ml}$ of a $0.1 \mathrm{M} \mathrm{CaCl}_{2}$ aqueous solution (adjusted to $\mathrm{pH} 8.5$ with aqueous $\mathrm{NH}_{3}$ ) was added dropwise at a rate of $1 \mathrm{ml} \mathrm{min}^{-1}$ to a $45 \mathrm{ml}$ aqueous solution of the G0.5 PAMAM dendrimer under gentle stirring at $30^{\circ} \mathrm{C}$ under $\mathrm{N}_{2}$. After mixing the reaction solution during a different time period from $3 \mathrm{~min}$ to $24 \mathrm{~h}, 2.5 \mathrm{ml}$ of a $0.1 \mathrm{M}\left(\mathrm{NH}_{4}\right)_{2} \mathrm{CO}_{3}$ aqueous solution (adjusted to $\mathrm{pH} 10.0$ with aqueous $\mathrm{NH}_{3}$ ) was added dropwise at a rate of $1 \mathrm{ml} \mathrm{min}^{-1}$ into the reaction solution under $\mathrm{N}_{2}$. This solution was stored at $30^{\circ} \mathrm{C}$ for 1 day with gentle stirring. The precipitated $\mathrm{CaCO}_{3}$ product was collected using a $0.2-\mu \mathrm{m}$-pore-sized membrane filter and washed with water several times. It was then dried at room temperature under reduced pressure.

\section{RESULTS AND DISCUSSION}

Effect of the incubation time of the G0.5 PAMAM dendrimer- $\mathrm{CaCl}_{2}$ solution on the formation of calcium carbonate particles

The G0.5 PAMAM dendrimer (G0.5) was used to study the influence of the incubation time of the dendrimer- $\mathrm{CaCl}_{2}$ solution on the formation of calcium carbonate particles. $\mathrm{A} \mathrm{CaCl}_{2}$ aqueous solution (adjusted to $\mathrm{pH} 8.5$ with aqueous $\mathrm{NH}_{3}$ ) was added to an aqueous solution of G0.5 (adjusted to $\mathrm{pH} 11$ with aqueous $\mathrm{NaOH}$ ) and stirred at $30^{\circ} \mathrm{C}$. No turbidity of the solution was observed before the addition of ammonium carbonate, even after incubation for $24 \mathrm{~h}$. After an aqueous ammonium carbonate solution was added to the reaction mixture at different time periods (from $3 \mathrm{~min}$ to $24 \mathrm{~h}$ ), the solution became turbid. The reaction mixtures were stored at $30^{\circ} \mathrm{C}$ for 1 day, and the products were collected. The $\mathrm{CaCO}_{3}$ crystal phases of the obtained products were characterized by FT-IR analysis (Figure 2). Both products obtained from the incubation time of 1 and $24 \mathrm{~h}$ showed two bands at 877 and $745 \mathrm{~cm}^{-1}$ by FT-IR, indicating vaterite formation. The products obtained from the incubation time of $3 \mathrm{~min}$ showed that the bands at 874 and $712 \mathrm{~cm}^{-1}$ assignable to calcite coexisted with vaterite. ${ }^{16,17}$ The crystal phases of the obtained $\mathrm{CaCO}_{3}$ products were confirmed by X-ray diffraction analysis (Figure 3 ). The products obtained from the incubation time of 1 and $24 \mathrm{~h}$ consisted entirely of vaterite (>99\%). The fraction of calcite in the crystalline phase of the product obtained from the incubation time of 3 min was $36 \%$, as determined by Rao's equation. ${ }^{18}$

SEM observations show that all the obtained products are spherical particles (Figure 4). The average particle sizes of the spheres decreased

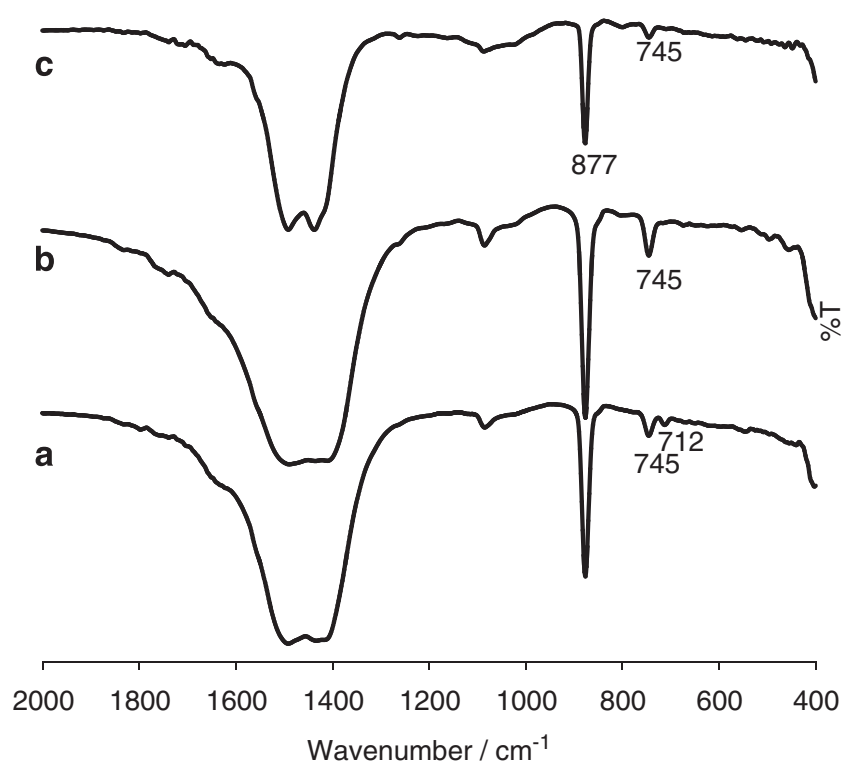

Figure 2 FT-IR spectra of calcium carbonate particles with G0.5 by the carbonate controlled-addition method at different incubation times of (a) $3 \mathrm{~min}$, (b) $1 \mathrm{~h}$ and (c) $24 \mathrm{~h}$.

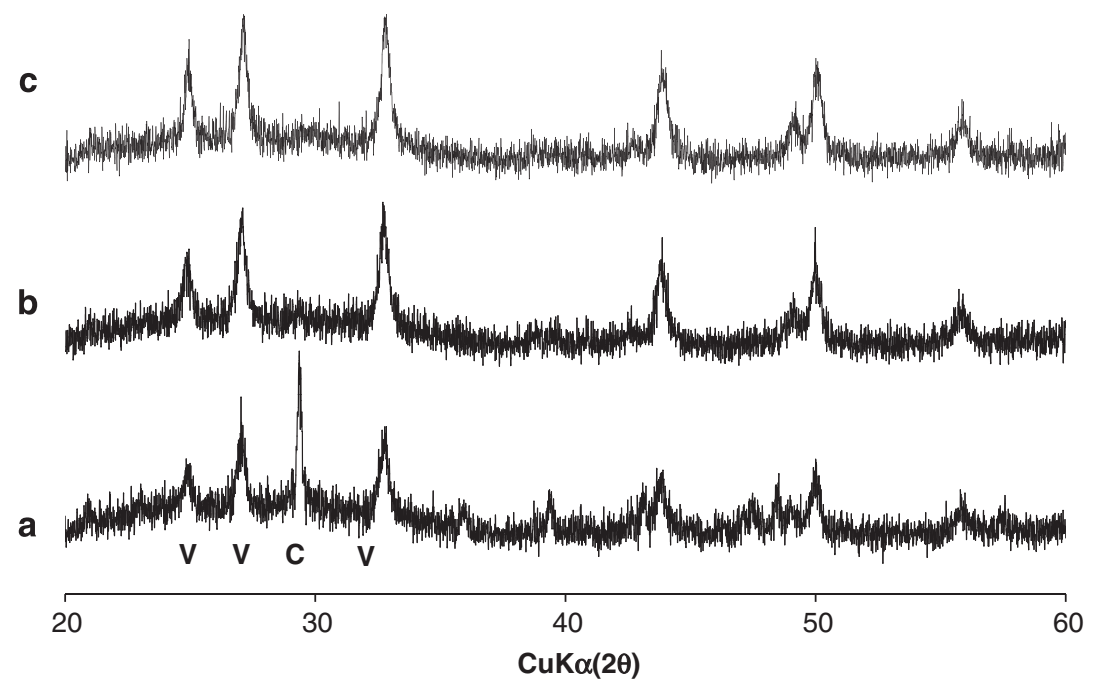

Figure 3 Comparison of X-ray diffraction (XRD) patterns of the calcium carbonate particles with G0.5 by the carbonate controlled-addition method at different incubation times of (a) $3 \mathrm{~min}$, (b) $1 \mathrm{~h}$ and (c) $24 \mathrm{~h}$. The XRD pattern characteristics for calcite are a d-spacing/2 $\theta$ peak of $3.04 \AA / 29.4^{\circ}$ corresponding to $h k l 104$. For vaterite, they are d-spacing/2 $\theta$ peaks at $3.58 \AA / 24.9^{\circ}, 3.3 \AA / 27^{\circ}$ and $2.73 \AA / 32.8^{\circ}$, corresponding to $h k l 110,111$ and 112 , respectively. 

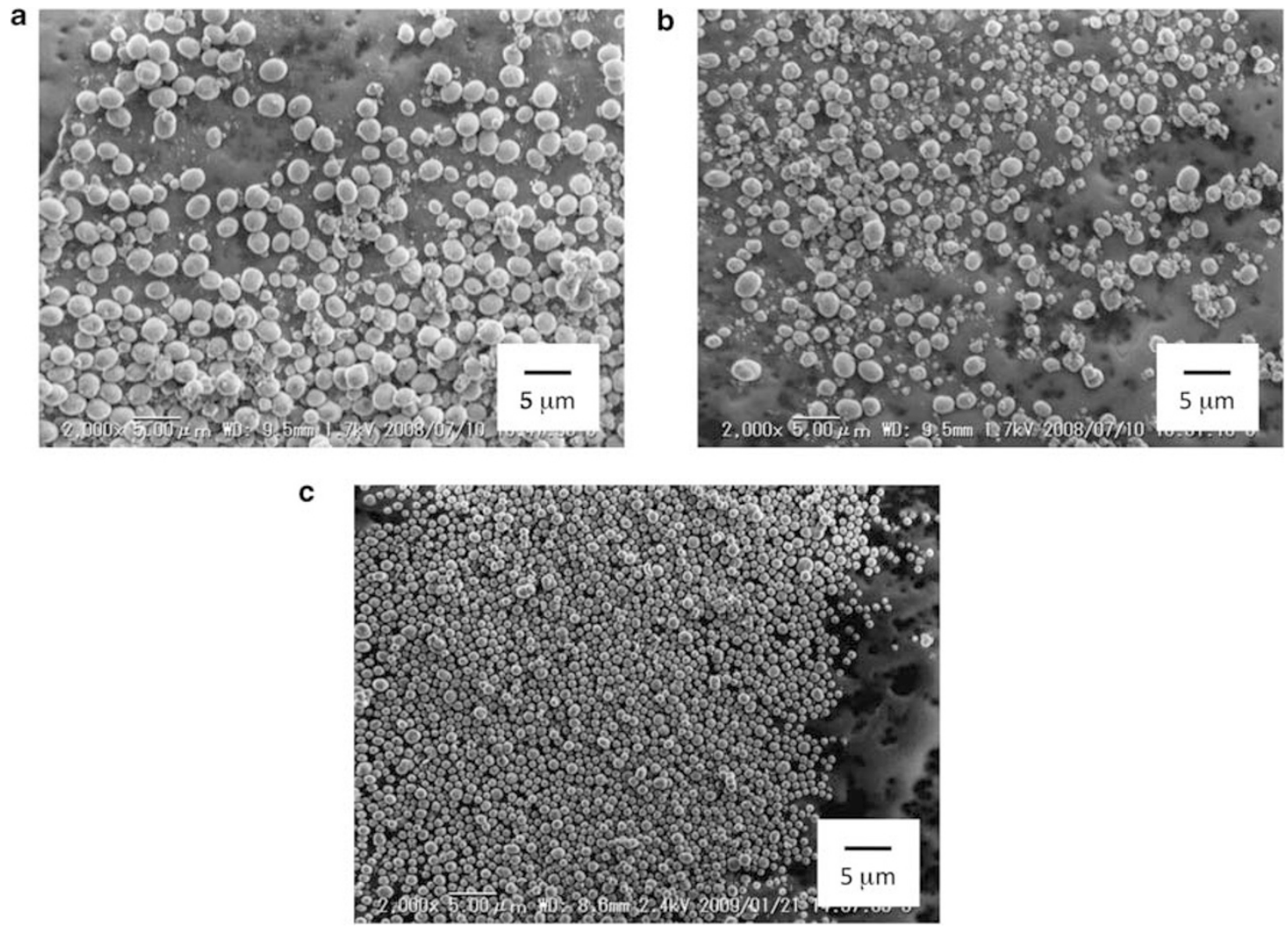

Figure $4 \mathrm{SEM}$ images of the products by the addition of $\left(\mathrm{NH}_{4}\right)_{2} \mathrm{CO}_{3}$ after incubating the G0.5- $\mathrm{CaCl}_{2}$ solution for (a) $3 \mathrm{~min}$, (b) $1 \mathrm{~h}$ and (c) $24 \mathrm{~h}$.

from $2.2 \pm 0.2$ to $0.61 \pm 0.24 \mu \mathrm{m}$ with an increase in the incubation time of the $\mathrm{G} 0.5-\mathrm{CaCl}_{2}$ solution from $3 \mathrm{~min}$ to $24 \mathrm{~h}$, respectively. These results indicate that the particle sizes of the spheres were controlled simply by changing the incubation time of the aqueous carbonate reagent in the $\mathrm{G} 0.5-\mathrm{CaCl}_{2}$ solution. The present results demonstrate that the interaction and reaction kinetics of the G0.5$\mathrm{Ca}^{2+}$ complex have an important role in the controlled morphology of spherical $\mathrm{CaCO}_{3}$ particles.

The compositions of the spheres were estimated by TGA (Figure 5). The results are summarized in Table 1 . The samples were dried under a reduced pressure at room temperature for more than 3 days to remove physically adsorbed water from the surfaces of the particles. The TGA analysis showed that the content of $\mathrm{H}_{2} \mathrm{O}$ in the particles decreased from 2.8 to $1.9 \mathrm{wt} \%$ on an increase in the incubation time of the $\mathrm{G} 0.5-\mathrm{CaCl}_{2}$ solution. The weight loss in the temperature range between 500 and $700{ }^{\circ} \mathrm{C}$ is $43-44 \%$, which is in reasonable agreement with the theoretical loss of $44 \mathrm{wt} \%$, which is attributed to the decomposition of $\mathrm{CaCO}_{3}$ into $\mathrm{CaO}$. Thus, the amount of residue at $500{ }^{\circ} \mathrm{C}$ was estimated as the contents of $\mathrm{CaCO}_{3}$ in the obtained samples. Weight loss at $200-500^{\circ} \mathrm{C}$ was due to the decomposition of the organic parts of the products. The contents of the organic parts in the three products were almost constant at around $4 \mathrm{wt} \%$.

Vaterite is thermodynamically most unstable in the three crystal structures. It is well known that vaterite transforms into thermodynamically stable calcite through a solvent-mediated process. ${ }^{19} \mathrm{We}$ checked the phase transformation of the vaterite particles in an aqueous solution at a longer incubation at $30^{\circ} \mathrm{C}$. The results are summarized in Table 2 . When the products were continuously kept in the reaction mixtures for 3 days, the $\mathrm{CaCO}_{3}$ phase of the precipitates

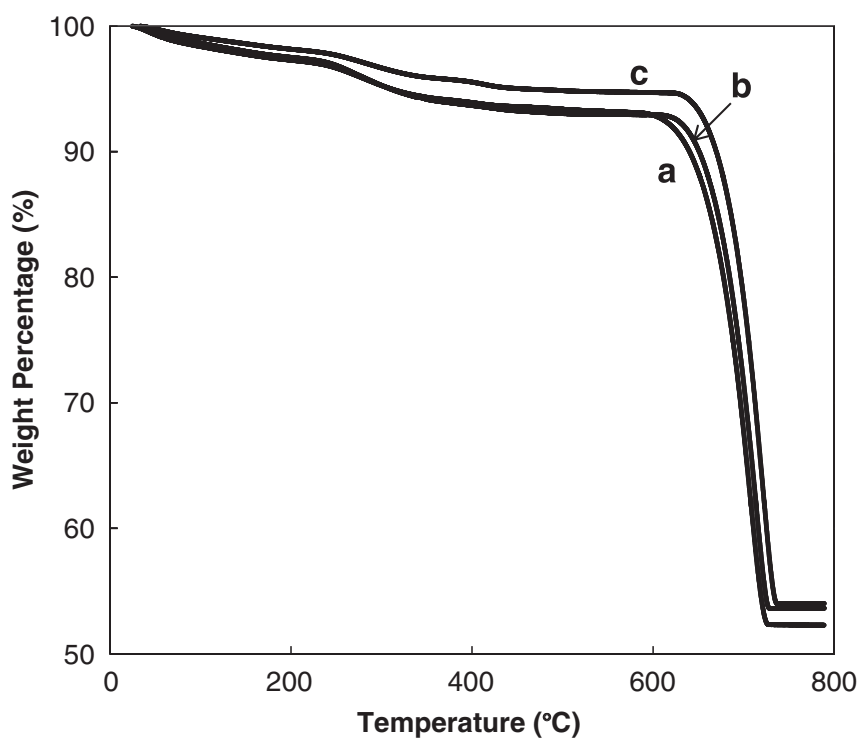

Figure 5 TGA thermographs of the calcium carbonate particles with G0.5 by the carbonate controlled-addition method at different incubation times of (a) $3 \mathrm{~min},(\mathrm{~b}) 60 \mathrm{~min}$ and (c) $24 \mathrm{~h}$.

obtained after incubating the G0.5- $\mathrm{CaCl}_{2}$ solution for $3 \mathrm{~min}$ and $1 \mathrm{~h}$ was calcite. However, the product after incubating for $24 \mathrm{~h}$ was vaterite. The average particle size of the spheres was $0.69 \pm 0.07 \mu \mathrm{m}$, which was almost the same as that of the particles isolated after 1 day of incubation. This result indicates that the vaterite surfaces obtained 
Table 1 Effect of the incubation times of the $\mathrm{G} 0.5-\mathrm{CaCl}_{3}$ solution on mineralization of $\mathrm{CaCO}_{3}{ }^{\mathrm{a}}$

\begin{tabular}{|c|c|c|c|c|c|c|}
\hline Sample number & Incubation time & Polymorphism ${ }^{\mathrm{b}}$ & $\begin{array}{l}\text { Particle size of } \mathrm{CaCO}_{3} \\
(\mu m)^{c}\end{array}$ & Yield $(\%)^{\mathrm{d}}$ & $\begin{array}{c}\text { Adsorbed amount of } \mathrm{H}_{2} \mathrm{O} \\
\text { on particlese (wt\%) }\end{array}$ & $\begin{array}{c}\text { Adsorbed amount of G0.5 } \\
\text { on particlese (wt\%) }\end{array}$ \\
\hline 1 & $3 \mathrm{~min}$ & Vaterite $>$ calcite & $2.2 \pm 0.2$ & 86 & 2.8 & 4.0 \\
\hline 2 & $1 \mathrm{~h}$ & Vaterite & $1.1 \pm 0.2$ & 73 & 2.6 & 4.5 \\
\hline 3 & $24 \mathrm{~h}$ & Vaterite & $0.61 \pm 0.24$ & 90 & 1.8 & 3.3 \\
\hline
\end{tabular}

Abbreviations: FT-IR, Fourier transform infrared; SEM, scanning electron microscopy; TGA, thermogravimetric analysis; XRD, X-ray diffraction.

aExperimental condition: $\left[\mathrm{Ca}^{2+}\right]=\left[\mathrm{CO}_{3}{ }^{2-}\right]=25 \mathrm{~mm} ;[-\mathrm{COONa}]:\left[\mathrm{Ca}^{2+}\right]=4: 1.25$; the $\mathrm{pH}$ value of the dendrimer aqueous solution was adjusted to 11 by a dilute aqueous solution of $\mathrm{NaOH}$. Every sample was made at least three times to check the reproducibility.

bolymorphism was characterized by FT-IR and XRD.

CThe sizes of particles were measured by SEM.
CTolymorphism was characterized by FTR and

${ }^{\mathrm{d}}$ The yield was calculated by the final crystal weights compared with theoretical weights of $\mathrm{CaCO}_{3}$ from injected calcium reagents.

eThe adsorbed amounts of water and G0.5 were measured by TGA (heating rate: $10^{\circ} \mathrm{C} \mathrm{min}^{-1}$ under air atmosphere).

Table 2 Long-term stability of the obtained $\mathrm{CaCO}_{3}$ particles incubated in the reaction solution for 3 days $^{a}$

\begin{tabular}{lllcc}
\hline $\begin{array}{l}\text { Sample } \\
\text { number }\end{array}$ & $\begin{array}{l}\text { Incubation } \\
\text { time }\end{array}$ & Polymorphism & $\begin{array}{c}\text { Particle size } \\
\text { of } \mathrm{CaCO}_{3}(\mu \mathrm{m})^{\mathrm{c}}\end{array}$ & $\begin{array}{l}\text { Yield } \\
(\%)^{\mathrm{d}}\end{array}$ \\
\hline 4 & $3 \mathrm{~min}$ & Calcite & $2.9 \pm 0.3$ & 85 \\
5 & $1 \mathrm{~h}$ & Calcite & $2.0 \pm 0.2$ & 63 \\
6 & $24 \mathrm{~h}$ & Vaterite & $0.69 \pm 0.07$ & 71
\end{tabular}

Abbreviations: FT-IR, Fourier transform infrared; SEM, scanning electron microscopy; XRD, X-ray diffraction.

aExperimental condition was the same as that of Table 1.

bPolymorphism was characterized by FT-IR and XRD.

${ }^{\mathrm{C}}$ The sizes of particles were measured by SEM.

dThe yield was calculated by the final crystal weights compared with theoretical weights of $\mathrm{CaCO}_{3}$ from injected calcium reagents.

after incubating for $24 \mathrm{~h}$ were stabilized by the carboxylate-terminated dendrimer, which prevented phase transformation. In the case of the vaterite particles obtained from the shorter incubation time, the binding strength between G0.5 and the surfaces of the vaterite particles was not strong enough to prevent phase transformation into calcite.

The morphologies of both the obtained calcite particles were not typical rhombohedral crystals but ellipsoid shapes (Figure 6). The average particle sizes of the spheres decreased from $2.9 \pm 0.3$ to $2.0 \pm 0.2 \mu \mathrm{m}$ by increasing the incubation time of the $\mathrm{G} 0.5-\mathrm{CaCl}_{2}$ solution from $3 \mathrm{~min}$ to $1 \mathrm{~h}$, respectively. The TGA analysis indicated that the content of the organic moieties in the product of sample number 5 in Table 2 was $4.5 \mathrm{wt} \%$. These results suggest that the dendrimer-vaterite particles were transformed into calcite particles with the dendrimer.

The stabilities of the isolated and dried vaterite particles were evaluated in fresh water. The crystal products incubated in the aqueous solution for 1 day were filtered and washed with water three times. Thereafter, the isolated crystals were placed in fresh water for further incubation for 7 days at room temperature. All the products obtained from incubation times of $3 \mathrm{~min}, 1 \mathrm{~h}$ and $24 \mathrm{~h}$ were vaterite, as determined by FT-IR analysis. Current results indicate that the isolated and dried vaterite particles modified with the dendrimer exhibited a strong stabilizing effect that prevented phase transformation.

\section{Effect of the generation number of dendrimers}

Precipitation of $\mathrm{CaCO}_{3}$ in the presence of the G1.5 PAMAM dendrimer (G1.5) was also carried out under the same conditions. The results are summarized in Table 3. The products obtained with G1.5 after incubating the dendrimer- $\mathrm{CaCl}_{2}$ solution for $3 \mathrm{~min}$ and $1 \mathrm{~h}$ showed two bands at 877 and $745 \mathrm{~cm}^{-1}$ by FT-IR, indicating vaterite formation (Figures $7 \mathrm{a}$ and $\mathrm{b}$ ). The FT-IR analysis indicates that the

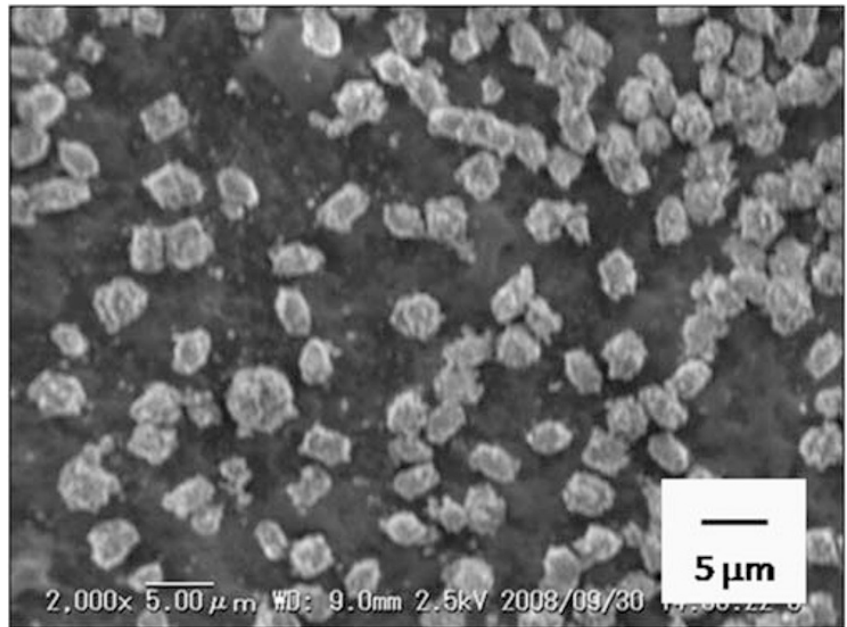

Figure 6 SEM images of products incubated in the reaction solution for 3 days by the addition of $\left(\mathrm{NH}_{4}\right)_{2} \mathrm{CO}_{3}$ after incubating the $\mathrm{GO} .5-\mathrm{CaCl}_{2}$ solution for $3 \mathrm{~min}$.

crystal product obtained after incubating for $24 \mathrm{~h}$ was a mixture of vaterite and calcite (Figure 7c). The SEM analysis of the products obtained from the incubation times of $3 \mathrm{~min}$ and $1 \mathrm{~h}$ shows spherical particles (Supplementary Figures S2a and b). The average particle sizes of the two spheres are almost the same. The SEM analysis of the product obtained after incubating for $24 \mathrm{~h}$ shows two morphologies, spherical and dumbbell-shaped microparticles (Figure 8). The size of the latter was $0.5 \pm 0.1 \mu \mathrm{m}$ in diameter and $1.4 \pm 0.3 \mu \mathrm{m}$ in length. The average particle size of the spheres was $1.1 \pm 0.1 \mu \mathrm{m}$. The average particle size of spheres decreased with an increasing incubation time of $1-24 \mathrm{~h}$.

\section{Crystal formation mechanism}

SEM images of the interior of cracked vaterite particles obtained after incubating for $1 \mathrm{~h}$ using G0.5 (sample number 2 of Table 1) are shown in Figure 9. The characteristic radiating features were observed in the crystals, which were formed by a spherulitic growth mechanism. ${ }^{20}$ In this growth process, the mixing of $\mathrm{Ca}^{2+}$ and carbonate ions results in the formation of amorphous $\mathrm{CaCO}_{3}$, which transforms within minutes to produce crystalline vaterite. Previously, we found that similar vaterite particles, which were formed by the spherulitic growth mechanism, were obtained by delaying the addition of PAA. ${ }^{21}$ It was assumed that PAA was mostly adsorbed on the surfaces of the final vaterite particles. In that system, the initially formed amorphous precursors might grow and transform into larger-sized vaterite particles before the addition of PAA. Thus, we assumed that the dendrimer was mostly adsorbed on 
Table 3 Effect of the incubation times of the $\mathrm{G} 1.5-\mathrm{CaCl}_{3}$ solution on mineralization of $\mathrm{CaCO}_{3}{ }^{\mathrm{a}}$

\begin{tabular}{lllll}
\hline Sample number & Incubation time & Polymorphism ${ }^{\mathrm{b}}$ & Shape $^{\mathrm{c}}$ & Particle size of CaCO $_{3}(\mu \mathrm{m})^{\mathrm{c}}$ \\
\hline 7 & $3 \mathrm{~min}$ & Vaterite & Sphere & $2.0 \pm 0.2$ \\
8 & $1 \mathrm{~h}$ & Vaterite & Sphere & $2.3 \pm 0.2$ \\
9 & Calcite+vaterite & Dumbbell & $1.4 \pm 0.3,0.50 \pm 0.08$ \\
& & & Sphere & $1.1 \pm 0.1$ \\
\hline
\end{tabular}

Abbreviations: FT-IR, Fourier transform infrared; SEM, scanning electron microscopy; XRD, X-ray diffraction.

a Experimental condition: $\left[\mathrm{Ca}^{2+}\right]=\left[\mathrm{CO}_{3}{ }^{2-}\right]=25 \mathrm{~mm},[-\mathrm{COONa}]:\left[\mathrm{Ca}^{2+}\right]=4: 1.25$, the $\mathrm{pH}$ value of the dendrimer aqueous solution was adjusted to 11 by a dilute aqueous solution of NaOH. Every sample was made at least two times to check the reproducibility.

bolymorphism was characterized by FT-IR and XRD.

'The shape and sizes of particles were measured by SEM.

dThe yield was calculated by the final crystal weights compared with theoretical weights of $\mathrm{CaCO}_{3}$ from injected calcium reagents.

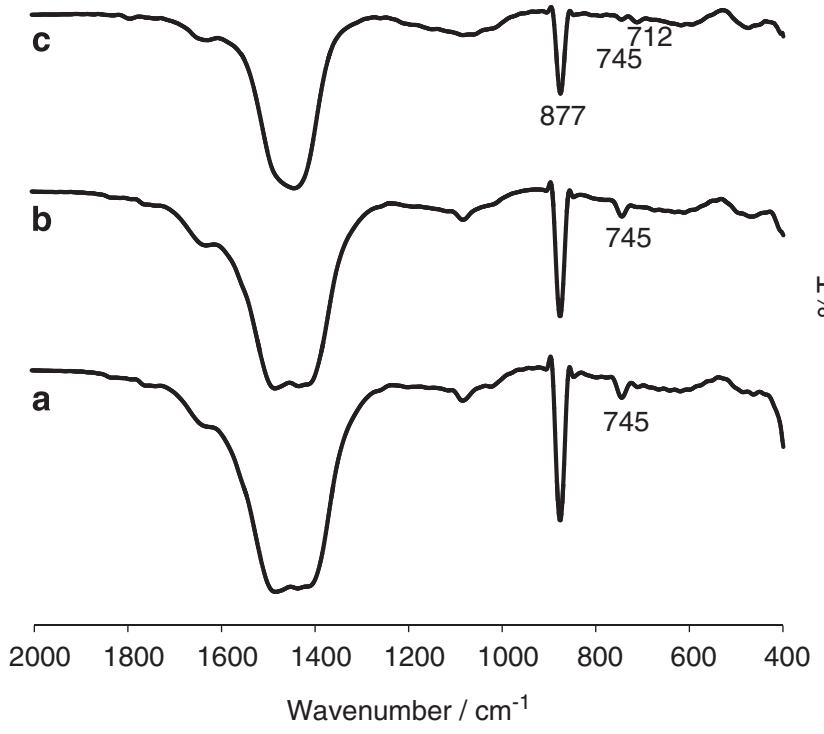

Figure 7 FT-IR spectra of calcium carbonate particles with G1.5 by the carbonate controlled-addition method at different incubation times of (a) $3 \mathrm{~min}$, (b) $1 \mathrm{~h}$ and (c) $24 \mathrm{~h}$.

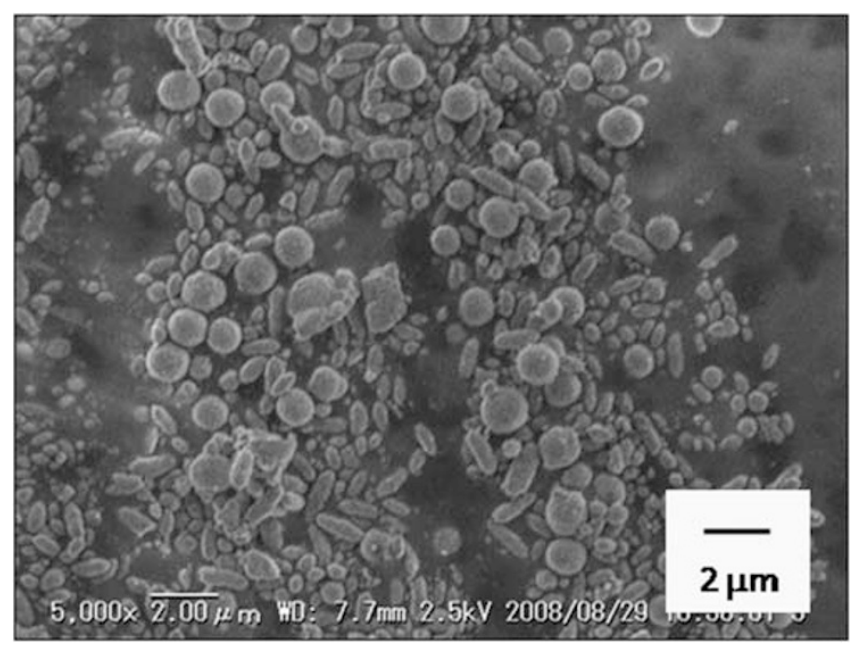

Figure $8 \mathrm{SEM}$ images of the products by the addition of $\left(\mathrm{NH}_{4}\right)_{2} \mathrm{CO}_{3}$ after incubating the $\mathrm{G} 1.5-\mathrm{CaCl}_{2}$ solution for $24 \mathrm{~h}$.

the surfaces of the final vaterite particles in the present carbonate controlled-addition method.

The so-called 'Eigen mechanism' of a metal ion complex formation reaction proposes the rate-determining step to be the loss of water

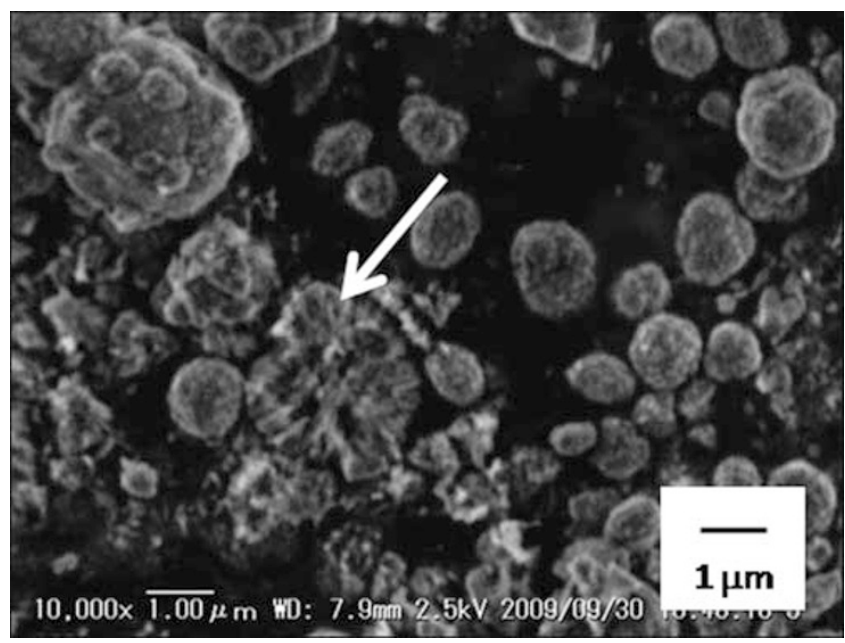

Figure 9 SEM image in the interior of the cracked open vaterite particles (white arrow) of sample number 2 in Table 1.

from a primary coordination sphere of a metal ion after the metal ion has formed an outer sphere complex (or solvent-separated ion pair) with an incoming ligand. ${ }^{22}$ The complexation of poly(amino carboxylate) ligands such as EDTA, EGTA and CDTA with $\mathrm{Ca}^{2+}$ ions has been found to involve rapidly formed intermediates that convert slowly into final products. ${ }^{23}$ The conversion of intermediates into final complexes involves a process of simultaneously stripping several water molecules from the first-coordination spheres of the $\mathrm{Ca}^{2+}$ ions. The effect of replacement of an acetate group by a propionate group such as the half-generation PAMAM dendrimers results in a decrease in affinity of the ligand for metal ions. ${ }^{24}$

The precipitation of $\mathrm{CaCO}_{3}$ in the presence of EDTA was carried out under the same conditions as Table 1 . Although a small amount of calcite particles (yield 23\%) was obtained when an EDTA-Ca ${ }^{2+}$ complex was incubated for $3 \mathrm{~min}$, no $\mathrm{CaCO}_{3}$ was observed when the EDTA- $\mathrm{Ca}^{2+}$ complex was incubated for $1 \mathrm{~h}$ or $24 \mathrm{~h}$. The stable EDTA- $\mathrm{Ca}^{2+}$ complex in the final state may inhibit the formation of $\mathrm{CaCO}_{3}$ because no $\mathrm{Ca}^{2+}$ ions dissociate during the crystallization process after the addition of carbonate ions.

A $\mathrm{CaCO}_{3}$ particle formation mechanism with dendrimers is proposed as follows (Figure 10): In the early stage of the G0.5- $\mathrm{Ca}^{2+}$ complexation process, the $\mathrm{G} 0.5-\mathrm{Ca}^{2+}$ complex in the intermediate state might be predominantly formed. The intermediate form would tend to dissociate during the crystallization process after the addition of carbonate ions. The initially formed amorphous $\mathrm{CaCO}_{3}$ might grow and transform into larger-sized vaterite particles before readsorption of G0.5 on the surfaces of calcium carbonate particles, which prevents aggregation of the amorphous $\mathrm{CaCO}_{3}$. The $\mathrm{G} 0.5-\mathrm{Ca}^{2+}$ complex in the 

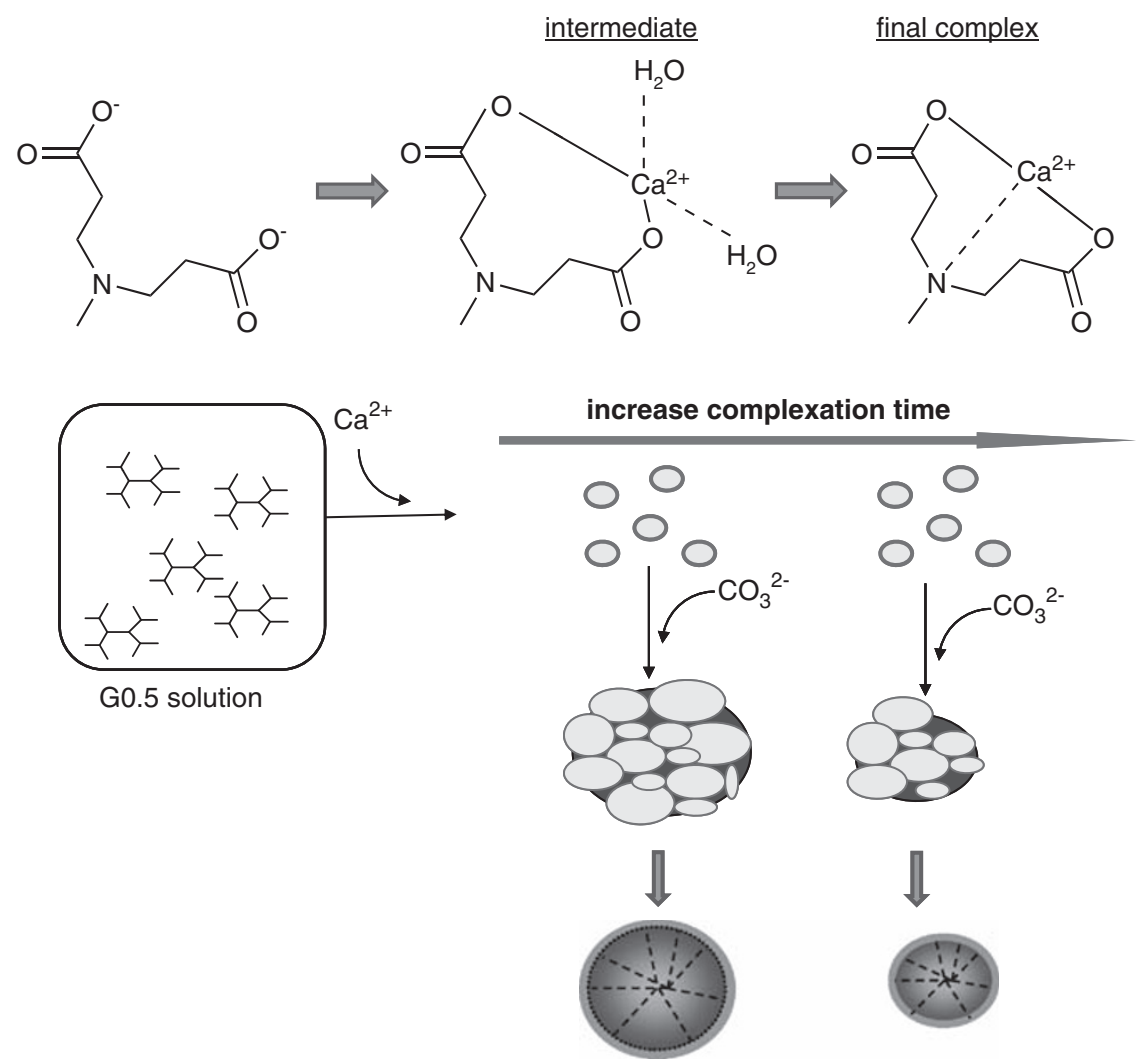

Figure 10 Schematic depiction of the formation of the $\mathrm{CaCO}_{3}$ spherulites and the transformation from the amorphous phase to vaterite. Yellow and gray spheres designate amorphous $\mathrm{CaCO}_{3}$ and vaterite, respectively. Red circles indicate adsorbed $\mathrm{GO} .5$ on the surfaces of $\mathrm{CaCO}_{3}$. A full color version of this figure is available at Polymer Journal online.

intermediate form may convert into the final complex with an increase in incubation time. The stability of the final complex is considerably higher than that of the intermediate complex. Therefore, the G0.5-Ca ${ }^{2+}$ complex in the final state would tend to retain its form during the crystallization process, which may inhibit the growth of the initially formed amorphous $\mathrm{CaCO}_{3}$ just after the addition of carbonate ions.

The number of calcium ions on anionic PAMAM dendrimers is considerably higher for the later generation than for the early generation because of increased interior nitrogen moieties under the same -COONa concentration. ${ }^{25}$ The stable G1.5- $\mathrm{Ca}^{2+}$ complex in the final state may inhibit stabilization of the resulting surface of vaterite particles. Therefore, the crystal product obtained from the incubation of the G1.5- $\mathrm{Ca}^{2+}$ complex for $24 \mathrm{~h}$ was a mixture of vaterite and calcite.

\section{CONCLUSIONS}

In this study, we demonstrated that the interaction and reaction kinetics of the $\mathrm{Ca}^{2+}$ complex of the PAMAM dendrimer with carboxylate groups at the external surface have an important role in controlling the particle size and stabilization of $\mathrm{CaCO}_{3}$ when using the 'carbonate controlled-addition method'. An aqueous ammonium carbonate solution was added at different time periods $(3 \mathrm{~min}, 1 \mathrm{~h}$ or $24 \mathrm{~h}$ ) to an aqueous solution of G0.5 PAMAM dendrimer and $\mathrm{CaCl}_{2}$, and the reaction mixtures were maintained at $30^{\circ} \mathrm{C}$ for 1 day. Both crystal phases of the products obtained after incubating the dendrimer- $\mathrm{CaCl}_{2}$ solution for 1 and $24 \mathrm{~h}$ consisted entirely of vaterite. Incubating the $\mathrm{G} 0.5-\mathrm{CaCl}_{2}$ solution for $3 \mathrm{~min}$ produced vaterite particles that coexisted with calcite. The average particle sizes of the spheres decreased from $2.2 \pm 0.2$ to $0.61 \pm 0.24 \mu \mathrm{m}$ with an increase in the incubation time of the $\mathrm{G} 0.5-\mathrm{CaCl}_{2}$ solution from $3 \mathrm{~min}$ to $24 \mathrm{~h}$.

We also found that the stability of vaterite spheres increased with an increase in the incubation time of the $\mathrm{G} 0.5-\mathrm{CaCl}_{2}$ solution. Even the contents of the organic parts in the three products were almost the same at around $4 \mathrm{wt} \%$. When the products were continuously kept in the reaction mixtures for 3 days, the $\mathrm{CaCO}_{3}$ phase of the obtained precipitates from the addition of $\left(\mathrm{NH}_{4}\right)_{2} \mathrm{CO}_{3}$ after incubating the G0.5- $\mathrm{CaCl}_{2}$ solution for $3 \mathrm{~min}$ and $1 \mathrm{~h}$ was calcite. However, the product after incubating for $24 \mathrm{~h}$ was vaterite. In the case of the vaterite particles from the shorter incubation times of the $\mathrm{G} 0.5-\mathrm{CaCl}_{2}$ solution, the binding strength between the dendrimer and the surfaces of the vaterite particles was not strong enough to prevent phase transformation of vaterite into calcite. Our results indicate that the interaction and reaction kinetics of the dendrimer- $\mathrm{Ca}^{2+}$ complex have an important role in the mineralization of $\mathrm{CaCO}_{3}$.

Electronic supporting information available: Supplementary Figures S1 and S2 (see Supplementary Information). These materials are available via the Internet at http://www.spsj.or.jp/c5/pj/pj.htm

\section{ACKNOWLEDGEMENTS}

We are indebted to Dr A Narita and Professor Y Chujo (Kyoto University) for the TGA analysis.

1 Naka, K. Biomineralization I: Crystallization and Self-Organization Process (SpringerVerlag Berline, Heidelberg, 2007). 
2 Naka, K. Biomineralization II: Mineralization Using Synthetic Polymers and Templates (Springer-Verlag Berline, Heidelberg, (2007)).

3 Naka, K. \& Chujo, Y. Control of crystal nucleation and growth of calcium carbonate by synthetic substrates. Chem. Mater. 13, 3245-3259 (2001).

4 Estroff, L. A. \& Hamilton, A. D. At the interface of organic and inorganic chemistry: bioinspired synthesis of composite materials. Chem. Mater. 13, 3227-3235 (2001).

5 Sommerdijk, N.A.J.M. \& de With, G. Biomimetic $\mathrm{CaCO}_{3}$ mineralization using designer molecules and interfaces. Chem. Rev. 108, 4499-4550 (2008).

6 Meldrum, F. C. \& Cölfen, H. Controlling mineral morphologies and structures in biological and synthetic systems. Chem. Rev. 108, 4332-4432 (2008),

7 Küther, J., Seshadri, R., Knoll, W. \& Tremel, W. Templated growth of calcite, vaterite and aragonite crystals on self-assembled monolayers of substituted alkylthiols on gold. J. Mater. Chem. 8, 641-650 (1998).

8 Wei, H., Shen, Q., Zhao, Y., Wang, D. - J. \& Xu, D. - F. Influence of polyvinylpyrrolidone on the precipitation of calcium carbonate and on the transformation of vaterite to calcite. J. Cryst. Growth 250, 516-524 (2003).

9 Huang, S. -C., Naka, K. \& Chujo, Y. A. carbonate controlled-addition method for amorphous calcium carbonate spheres stabilized by poly(acrylic acid)s. Langmuir 23, 12086-12095 (2007).

10 Huang, S. -C., Naka, K. \& Chujo, Y. Effect of molecular weights of poly(acrylic acid) on crystallization of calcium carbonate by the delayed addition method. Polym. J. 40, 154-162 (2008).

11 Tomalia, D. A., Naylor, A. M. \& Goddard III, W. A. Starburst dendrimers: molecular-level control of size, shape, surface chemistry, topology, and flexibility from atoms to macroscopic matter. Angew. Chem. Int. Ed. Engl. 29, 138-175 (1990).

12 Naka, K., Tanaka, Y., Chujo, Y. \& Ito, Y. The effect of an anionic starburst dendrimer on the crystallization of $\mathrm{CacO}_{3}$ in aqueous solution. Chem. Commun. 1999, 1931-1932 (1999).

13 Naka, K., Tanaka, Y. \& Chujo, Y. The effect of anionic starburst dendrimers on the crystallization of $\mathrm{CacO}_{3}$ in aqueous solution: size control of spherical vaterite particles. Langmuir 18, 3655-3658 (2002).

14 Tomalia, D. A., Baker, H., Dewald, J., Hall, M., Kallos, G., Martin, S., Roeck, J., Ryder, J. \& Smith, P. A. New class of polymers: starburst-dendritic macromolecules. Polym. J. 17, 117-132 (1985).
15 Aoi, K., Itoh, K. \& Okada, M. Divergent/convergent joint approach with a half-protected initiator core to synthesize surface-block dendrimers. Macromolecules 30, 8072-8074 (1997).

16 Xu, G., Yao, N., Aksay, I. A. \& Groves, J. T. Biomimetic synthesis of macroscopic-scale calcium carbonate thin films. evidence for a multistep assembly process. J. Am. Chem. Soc. 120, 11977-11985 (1998).

17 Chakrabarty, D. \& Mahapatra, S. Aragonite crystals with unconventional morphologies. J. Mater. Chem. 9, 2953-2957 (1999).

18 Rao, M. S. Kinetics and mechanism of the transformation of vaterite to calcite. Bull. Chem. Soc. Jpn. 46, 1414-1417 (1973).

19 Lopezmacipe, A., Gomezmorales, J. \& Rodriguezclemente, R. Calcium carbonate precipitation from aqueous solutions containing aerosol OT. J. Cryst. Growth 166, 1015-1019 (1996).

20 Andreassen, J. -P. formation mechanism and morphology in precipitation of vaterite-nano aggregation or crystal growth? J. Cryst. Growth 274, 256-264 (2005).

21 Naka, K., Huang, S.- C. \& Chujo, Y. Formation of stable vaterite with poly(acrylic acid) by delay addition method. Langmuir 22, 7760-7767 (2006).

22 Carr, J. D. \& Swartzfager, D. G. Kinetics of the ligand exchange and dissociation reactions of calcium-aminocarboxylate complexes. J. Am. Chem. Soc. 97, 315-321 (1975).

$23 \mathrm{Wu}$, S. L., Johnson, K. A. \& Horrocks Jr, W. D. Kinetics of Formation of $\mathrm{Ca}^{2+}$ complexes of acyclic and macrocyclic poly(amino carboxylate) ligands: bimolecular rate constants for the fully-deprotonated ligands reveal the effect of macrocyclic ligand constraints on the rate-determining conversions of rapidlyformed intermediates to the final complexes. Inorg. Chem. 36, 1884-1889 (1997).

24 Courtney, R. C., Chaberek Jr, S. \& Martell, A. E. Stability of metal chelates. VII. N, $N$ Ethylenediaminedipropionic acid and $N, N^{\prime}$-ethylenediaminetetrapropionic acid. J. Am. Chem. Soc. 75, 4814-4818 (1953).

25 Naka, K., Kobayashi, A. \& Chujo, Y. Effect of anionic 4.5-generation polyamidoamine dendrimers on the formation and structure of calcium carbonate polymorphs. Bull. Chem. Soc. Jpn. 75, 2541-2546 (2002).

Supplementary Information accompanies the paper on Polymer Journal website (http://www.nature.com/pj) 